\title{
Corrigendum
}

\section{ESPEI for efficient thermodynamic database development, modification, and uncertainty quantification: application to $\mathrm{Cu}-\mathrm{Mg}-\mathrm{CORRIGENDUM}$}

\section{Brandon Bocklund, Richard Otis, Aleksei Egorov, Abdulmonem Obaied, Irina Roslyakova, and Zi-Kui Liu}

doi: https://doi.org/10.1557/mrc.2019.59, Published by Materials Research Society with Cambridge University Press, 4 June 2019

In regards to the original publication of this article ${ }^{[1]}$, the authors would like to correct the following: the opening sentence of the caption for Figure 5a should read "Corner plot (a) of the parameters in the liquid phase."

\section{Reference}

1.B. Bocklund, R. Otis, A. Egorov, A. Obaied, I. Roslyakova and Z.-K. Liu: ESPEl for efficient thermodynamic database development, modification, and uncertainty quantification: application to Cu-Mg. MRS Commun. 9, 618-627 (2019). 